\title{
Globalnie czy lokalnie? Kulturowe uwarunkowania edukacji w Chinach
}

Streszczenie: Celem podjętych rozważań jest przedstawienie kulturowych uwarunkowań edukacji w Chinach w dobie globalizacji. Artykuł odpowiada na pytanie, czy w czasach globalnych przemian i swobodnego przepływu treści, znaczeń i rozwiązań oświatowych, edukacja w Chinach pozostaje wierna tradycji i wartościom lokalnym. Przedmiotem badań były system edukacyjny i rzeczywistość kulturowo-społeczna w okresie przemian. W treści artykułu wykorzystano badania zastane chińskich i zagranicznych autorów. Jako metodę badawczą wybrano analizę źródeł wtórnych, która pokazała, że mimo gwałtownych, globalnych zmian, chińska edukacja w swoich metodach i sposobach nauczania pozostaje wierna ideałom i założeniom chińskiej tożsamości, a dokonuje tego za pośrednictwem procesu kontekstualizacji.

Słowa kluczowe: pedagogika porównawcza, Chiny, edukacja w Chinach, system edukacyjny, globalizacja

Angielski komparatysta Michael Sadler pisał, że w poznaniu szeroko pojętej edukacji danego kraju niezbędne jest skierowanie uwagi na lokalne, kulturowe uwarunkowania systemu edukacyjnego (za: Redcliffe-Maud, 1973). Maria Manzon (2018) w interpretacji trendów badawczych w pedagogice porównawczej pisze, że z kolei klasycy tej dziedziny Fryderyk Shneider i Nicholas Hans uwrażliwili kolejne pokolenia komparatystów na badanie kontekstu edukacyjnego, jakim są charakterystyka narodu, geograficzna lokalizacja czy kultura. Dzięki takiej analizie możliwe jest poznanie, a także zdefiniowanie struktur systemów edukacyjnych, rządzących nimi praw, polityk czy ekonomii. Studiując kulturowe uwarunkowania systemu edukacyjnego, możliwe jest zrozumienie natury systemu edukacji, z którego wyrósł i na podstawie którego rozwinął się. Stąd też rozważania na temat kulturowych uwarunkowań edukacji trzeba uznać za ważne i istotne w procesie poznania.

Przeobrażenia edukacyjne, spowodowane zmianami globalizacyjnymi, urynkowieniem kolejnych przestrzeni społecznych, w tym edukacji, zmia- 
nami w strukturze społeczeństw sprawiły, że systemy edukacyjne zaczęto dostosowywać do nowej rzeczywistości. Wspomniane zmiany można zaobserwować także w edukacji chińskiej. Na ostatnim zjeździe Komunistycznej Partii Chin, w październiku 2017 roku, w przemowie do narodu przewodniczący Xi zauważył, że następstwa globalizacyjne, w tym międzynarodowe programy i standardy edukacyjne oraz urynkowienie edukacji, są obecne w chińskim dyskursie. Podkreślił, że Państwo Środka nigdy nie poświęciło bogatej tradycji edukacyjnej, ale nauczyło się korzystać z nowoczesnej edukacji, doświadczeń i badań. Chiny są unikatowe pod wieloma względami, a umiejętność dostosowania się do przemian zachodzących w społeczeństwie z uwzględnieniem własnej, wielkowiekowej tradycji stanowi o niekwestionowanej wyjątkowości społeczności Państwa Środka. Chiny pozostały aktywne w odbiorze globalnej kultury i trendów, co między innymi uczyniono przedmiotem poniższego artykułu.

Kierując się myślą i wskazówką klasyków, za cel poniższego artykułu postawiono przedstawienie i opisanie aktualnych kulturowych uwarunkowań edukacji w Chinach. Przedmiotem są kulturowe uwarunkowania edukacji w Państwie Środka na tle zmian i przeobrażeń globalizacyjnych. Pytanie główne brzmi: jaki jest kierunek uwarunkowań kulturowych edukacji we współczesnych Chinach?

Jako metodę badawczą wybrano analizę źródeł wtórnych i na tej podstawie zbudowano wiedzę kulturową i edukacyjną, wspartą wynikami i konkluzjami z danych powtórnie analizowanych. Jako źródła do analizy wykorzystano prace badawcze autorów chińskich i pozachińskich, aby uzyskać dwojaką perspektywę. Celem poniższego artykułu jest uzyskanie nowego koncepcyjnego ogniska nad kulturowymi uwarunkowaniami edukacji w Chinach poprzez przedstawienie przykładów rozwiązań edukacyjnych tkwiących w tradycji chińskiej i nowoczesności. W wyborze badań zastanych do analizy kryterium stanowiło: pochodzenie badacza (w celu zestawienia perspektywy chińskich i pozachińskiej), wybór przykładów odnoszących się bezpośrednio do konfucjańskich zasad i tradycji z uwzględnieniem perspektywy tożsamościowej - chińskiego „ja”, podejścia do uczenia się i nauczania z punktu widzenia jednostki i społeczności. Wybrano przykłady, które dotyczą edukacji od najmłodszych lat do momentu wejścia w sektor edukacji wyższej. Tłem rozważań są także wprowadzane reformy edukacyjne. Analizę uzupełniono o własne doświadczenia i obserwacje badawcze i pozabadawcze (jako uważnego obserwatora i uczestnika życia społecznego) poczynione w trakcie stażu naukowego w Bejing Normal Uniwersity w Pekinie w 2017 roku. Autorka 
nie miała dostępu do danych pierwotnych analizowanych wyników badań, a jedynie do ich finalnej wersji, czyli opublikowanych, opracowanych danych.

W pierwszej części artykułu autorka wyjaśnia związek edukacji i kultury. W dalszej kolejności opisano chińską kulturę poprzez pryzmat tradycyjnych wartości konfucjańskiej nauki. Całość kończą podsumowanie i wnioski.

\section{Edukacja i kultura w Chinach}

Kulturę możemy studiować pod różnym kątem. Przyjęto, że kultura to system znaczeń, podzielanych wartości, przekonań czy wierzeń, a także artefaktów powszechnie uznanych przez społeczeństwo (Sztompka, 2002). Osoby pochodzące $z$ tych samych kręgów kulturowych podzielają te same lub podobne poglądy, charakteryzują ich pewne wzory myślenia, odczuwania, czy sposób zachowania oparty na podzielanych znaczeniach. Geert Hofstede (2011) definiuje kulturę jako kolektywny system zaprogramowania umysłu, który wyróżnia członków danej społeczności od innych. Przekazywaniu kultury towarzyszy kilka procesów. Zdaniem Rogera Kessinga (1980) kultura jest przekazywana kolejnym pokoleniom za pośrednictwem procesu socjalizacji, w trakcie której jednostki uczą się jej. Z kolei w procesie enkulturacji jednostki dowiadują się, w jaki sposób stać się kompetentnym członkiem danej społeczności (Kessing, 1980). Akulturacja z kolei jest procesem, który umożliwia transfer z jednej kultury do drugiej (Mead, 1943). Wszystkie wspomniane procesy są znaczące dla edukacji, kiedy zależy nam na ustaleniu, które aspekty kultury (wiedza, umiejętności, wartości, postawy) są przekazywane z jednej grupy do drugiej, w przypadku kiedy mamy do czynienia $\mathrm{z}$ transmisją międzypokoleniową lub międzygrupową.

Poszukując związku kultury i edukacji, należy odwołać się do klasycznych koncepcji antropologicznych Margaret Mead (1943). Jedna z nich zakłada, że kulturowe sposoby interpretacji świata codziennego są obecne w systemie edukacji i kontynuowane w całym procesie LLL. Według autorki (Mead, 1943) edukacja jest kulturowym procesem, istotną społecznie i kulturową aktywnością podejmowaną przez człowieka, obecną w ciągu całego życia, elementarną, nieodzowną jego częścią. Można zatem twierdzić, że natura edukacji leży we wzbogacaniu potencjału ludzi, aby w przyszłości mogli prowadzić lepsze życie, wzbogacać siebie. Dzięki niej następuje przejście człowieka od natury z której się wywodzi, do społeczeństwa - cywilizacji, do której przynależy. Wszystkie społeczeństwa uczą, niektóre w sposób ustrukturyzowany, za pośrednictwem systemów szkolnych. 
Zdaniem innego klasyka, Yehudi Cohena (1971), edukacja kreuje głownie duchowe produkty, które są materializowane i przekazywane uczniom w postaci wiedzy i aplikowane jako doświadczenia, w celu wzbogacenia ich ludzkiego potencjału i wartości. Edukacja rozprzestrzenia i tworzy kulturę $\mathrm{w}$ procesie nauczania, gdyż jest to jej głównym zadaniem. Jerome Bruner (2006) zauważa, że edukacja nie jest samotną wyspą dryfująca po oceanie. Jest częścią kontynentu, elementem składowym większego obszaru społecznego. W świetle wskazanych słów trzeba pokreślić, że edukacja jest zależna od kultury, z której wyrosła. Stanowi kontynuację tejże kultury. Można także powiedzieć, że procesy edukacyjne mają miejsce (dzieją się) w określonym kulturowym kontekście, charakterystycznym i tożsamym dla każdego społeczeństwa.

Edukacja jako element kultury jest także produktem politycznym i ekonomicznym określonego czasu, a także przestrzeni, w której się znajduje jednak zarówno ekonomia, jak i siły polityczne częściej ulegają przeobrażeniom w porównaniu z kulturą, która wobec wymienionych jest bardziej stała, ma zdecydowanie bardziej długofalowy wpływ na kształt edukacji. Cztery podstawowe elementy procesu edukacji, to znaczy: nauczający, odbiorcy edukacji, istota edukacji i podejście do edukacji, znajdują się pod silnymi wpływami kultury. Inny klasyk - Florence Kluckhohn (1961) dochodzi do wniosków, że kultura kształtuje/wpływa na wartość i znaczenie edukacji w społeczeństwie, pracę nauczycieli, relacje nauczyciel-uczeń, cele edukacji, jej zawartość/treści; mówiąc bardziej ogólnie - cały system edukacyjny. Autorka dowodzi, że etnograficzne studia nad kulturą szkoły i klasy stanowią odzwierciedlenie doświadczeń kulturowych uczniów, wartości i norm przekazywanych kolejnym pokoleniom, zarówno tych intencjonalnych (zaplanowanych), jak i nieintencjonalnych. Szkoła kształci i wychowuje, bez względu na to, czy istnieje przyzwolenie i akceptacja takiego stanu rzeczy przez społeczeństwo. Można powiedzieć, że całość dzieje się w pewnym wymiarze poza świadomością podmiotów kształcenia, a nasze zaprogramowane umysły mają pochodzenie społeczne. To, co czyni świat i systemy edukacyjne ciekawym i intrygującym, to właśnie istniejące różnice.

Współczesna edukacja w Chinach oprawiona jest w silną kulturową konfucjańską ramę i stanowi ona pewne uniwersalne tło edukacyjne dla całej chińskiej mozaiki etnicznej (Mańkowska, 2017). Związane jest to z tradycją, jak i obowiązującymi prądami politycznymi. W chińskim przypadku wartości konfucjańskie wpływają na chińskie rodziny, nauczycieli bez względu na przynależność do grupy etnicznej (Gu, 2014). 
Wyjątkowość kultury chińskiej jest szczególnie widoczna, kiedy przyrównamy ją do kultur zachodnich. Chiński konfucjanizm jest unikatowy w swojej strukturze, gdyż na przestrzeni lat pozostawał kolejno pod wpływami taoizmu, buddyzmu i tradycji judeochrześcijańskiej. Zdaniem Gu (2014) wiele tradycji taoistycznych i buddaistycznych zostało włączonych do koncepcji neokonfucjanizmu za panowania dynastii Songów i Ming. Podstawową wartością konfucjańską jest xue zuo ren, co oznacza naukę siebie. Prawdziwie konfucjańska nauka to uczenie się dla samego siebie. Xue zuo ren w chińskim kontekście edukacyjnym oznacza: wyrafinowanie estetyczne, doskonałość moralną oraz religijność.

W konfucjańskiej etyce „ja” jest pojmowane w kontekście relacji międzyludzkich. Nauka jest rozumiana jako doskonalenie siebie w grupie społecznej. Zgodnie z nauką konfucjanizmu tylko dzięki wzmacnianiu więzi z grupą społeczną może nastąpić rozwój własnej osobowości. Uczenie się od siebie nawzajem jest wzbogacające i przypisuje się mu niezwykłe właściwości. Najlepiej tę zależność wyjaśnia koncepcja wzajemności. Kształtowanie relacji nie polega na narzucaniu swojej woli i nadużywaniu władzy. Dla przykładu, relacje ojca z synem są oparte na wzajemności i obopólności miłości oraz synowskim oddaniu. Nauka człowieczeństwa polega na pielęgnowaniu wzajemności w relacjach międzyludzkich oraz kultywowaniu cnotliwości. Konfucjanizm jest krytykowany za promowanie autorytaryzmu i bezkrytyczne posłuszeństwo, ale taka jednostronna interpretacja konfucjanizmu osłabia pierwotny zamiar i podstawowe wartości konfucjańskie.

Według Da Xue ${ }^{1}$ oraz Zhong Yhong ${ }^{2}$ konfucjanizm dotyczy: ge-wu - odkrywania pomysłów, zhi-zhi - pogoni za wiedzą, zheng-xin - dyscypliny serca oraz Cheng-yi - szczerości swoich działań. Doskonalenie siebie doprowadzi do qi-jia - harmonii rodziny, zhi-guo - zarządzania narodem oraz ping-tian-xia - pokoju w świecie. Z powyższego wynika, że uczyć się to stawać się dobrą osobą. W nauce konfucjańskiej wyróżnia się aż pięć obszarów w procesie uczenia się człowieczeństwa: estetyczny, społeczny, historyczny, polityczny oraz pozaziemski (duchowy) - w tym sensie możemy powiedzieć, że Konfucjusz był prekursorem holistycznej edukacji.

1 DÀXUÉ (Wielka nauka) - jedna z najważniejszych ksiąg konfucjanizmu, zw. Wielką Nauką.

2 ZHONG YONG (Doktryna Środka) - uzasadniająca metafizycznie konfucjańską filozofię społeczną i łącząca pewne idee konfucjanizmu, buddyzmu i taoizmu. 


\section{Globalne trendy w chińskiej edukacji, czyli gdzie tradycja spotyka się z nowoczesnością. Przykłady praktycznych rozwiązań}

Globalizacja odcisnęła trwały ślad we wszystkich sferach naszego życia. Jak zauważa Ronald Robertson (1992), mamy do czynienia z kompresją świata oraz jednocześnie z intensyfikacją świadomości ludzi na świecie, w kwestii przenikania się tożsamości, wzorów kultury czy edukacji właśnie. Zasadniczo stanowiska badaczy wobec procesów globalizacyjnych są podzielone. Z jednej strony dość wyraźne są głosy przestrzegające nas przed unifikacją kultury, a z drugiej strony, chociażby w podejściu antropologicznym, różnorodność kulturowa i swobodny przepływ kultur (dyfuzja kultury) działa na korzyść obywateli świata - dzięki niej możemy poznać i uczyć się od obcych kultur, tym samym budować tożsamość, czerpać lub odrzucać wzory kulturowe, poznawać rozwiązania edukacyjne.

George Ritzer (2009) do zobrazowania następstw współczesnej kulturowej homogenizacji użył określenia macdonaldyzacji. Niestety, ilekroć w czasach globalnych mamy do czynienia z procesami przepływu kultury, najczęściej dzieje się to w kierunku od centrum do peryferii, gdzie centrum to kultura i trendy zachodnie. Zgodnie z powyższym na świecie moglibyśmy spodziewać się globalnej pedagogiki, która wyznaczałaby jednakowe trendy dla wszystkich. Tak jednak się nie stało i najprawdopodobniej nigdy się to nie wydarzy, a przykład chiński stanowi ciekawą egzemplifikację. Richard E. Nisbett (2009) wyjaśnia, że „[...]Wschód coraz swobodniej sięga po zachodnie idee. To, jak one na niego wpłyną, jakim transformacjom ulegną podczas przepuszczania ich przez filtr Wschodu i jakie modyfikacje zostaną przyjęte [...], można zgadywać, przyglądając się różnicom [...]" (s. 45). Grace Choy (2017) zauważa, że rozwój badań nad zachodnią praktyką edukacyjną i „wyławianie” tzw. przykładów najlepszych praktyk sprawiło, iż zachodnie modele teorii edukacyjnych i pedagogicznych „wkradły się" do chińskiego kontekstu, a wybrane rozwiązania funkcjonują w systemie. Współcześnie są szczególnie obecne i żywe w edukacji w Hongkongu, na Tajwanie czy w Macao. W Chinach kontynentalnych sytuacja jest zróżnicowana. Dla przykładu, w chińskiej podstawie programowej w Hongkongu (Hong Kong Special Administrative Region Government - HKSARG) do nauczania przedszkolnego o nazwie Kindergarten Education. Curriculum Guide (2017) można odnaleźć zagraniczne koncepcje Vygotskiego, Bredekampa, Katza, czy pedagogię Reg- 
gio Emilia oraz teorię zwielokrotnionej inteligencji Gardnera. Projekt ustawy był wypadkową współpracy polityków edukacyjnych, badaczy, naukowców, praktyków, i konsultowany w wielu prowincjach kraju. Okazało się, iż mimo prób implikacji podstawy w Chinach kontynentalnych jego pełna realizacja nie była możliwa, ze względu chociażby na zbyt liczne oddziały przedszkolne lub też brak wykwalifikowanej kadry na terenach wiejskich, która mogłaby sprostać globalnemu planowi edukacyjnemu. Wielu praktyków edukacyjnych informowało o rozbieżnościach w implementacji proponowanych zmian i apelowało o adaptację programów do lokalnych warunków kulturowych oraz fizycznych możliwości instytucji. Jako przyczynę niepowodzenia implementacji badacze Weipeng Yang oraz Hui Li (2019) podają, że proponowane rozwiązania edukacyjne nie idą w parze z kolektywistyczną chińską tradycją Chin kontynentalnych, gdzie indywidualizm, autonomia oraz rozwijanie krytycznego myślenia u podmiotów edukacyjnych ma kontekst lokalny. Jednym z wniosków i rekomendacji był apel, aby praktykę edukacyjną odpowiednią dla rozwoju (developmentally appropriate practice - DAP) zastąpić praktyką odpowiednią dla rozwoju i lokalnej kultury (developmentally and culturally appropriate practice DCAP lub culturaly adapter teaching CAT).

Chińska edukacja wyrosła na feudalnej kulturze (agrarnej tradycji) państwa. Przykład narodowego systemu egzaminacyjnego wyrósł ze wspomnianego systemu i był elementem kultury feudalizmu w Państwie Środka. W Świątyni Konfucjusza w Pekinie, w rycinach i opisie wyjaśniono tradycję egzaminowania w Chinach oraz podejmowania często heroicznych wysiłków edukacyjnych przez obywateli Państwa Środka. Otóż system silnej selekcji najlepszych osób od zawsze wpisany był w kulturę Chin i przetrwał ponad 1400 lat. Wywodzi się z tradycji egzaminowania aplikantów na stanowiska urzędnicze. W literaturze przedmiotu przykłady tragicznych w skutkach chińskich egzaminów „gaokao”, chińskiego egzaminacyjnego piekła, opisała Agnieszka Gromkowska-Melosik (2017). Warto jednak wyjaśnić poprzez pryzmat kultury, dlaczego tradycja egzaminowania jest tak żywa w społeczeństwie chińskim. Chińczycy wierzą, że - zgodnie z konfucjańską etyką - sukces osiąga się tylko przez ciężką pracę. W Chinach znaczenie talentu jest inaczej rozumiane. Talent w ujęciu europejskim praktycznie nie istnieje, a sukces osoby zależy tylko i wyłącznie od ciężkiej pracy i wysiłku włożonego w osiągnięcie założonych celów. W chińskim rozumieniu talenty się zdobywa, pracuje się na nie, a nie rodzi się z nimi. Wiedzy i edukacji, za którą stoi ciężka praca, Chińczycy przyznają ogromną wartość, a cytat z Dialogów Konfucjańskich potwierdza tę tezę: 
$\mathrm{Ci}$, którzy rodzą się mądrzy, są najwyższą kategorią ludzi.

$\mathrm{Ci}$, którzy stają się mądrzy poprzez naukę, są tuż za nimi.

Ci, którzy są mniej zdolni, a mimo to starają się uczyć, są kolejni.

$\mathrm{Ci}$, którzy są mniej zdolni, a mimo to nie próbują się uczyć, są najniższą kategorią człowieka.

Doskonalenie i dążenie do własnej perfekcji jest nieodłącznym elementem kultury chińskiej. Właśnie z tego powodu nieustanny rozwój osobisty, okupiony często kosztem zdrowia własnego i zaangażowania całej rodziny, jest jednym z elementów kultury edukacji w Chinach. W przekonaniu Chińczyków, wcale nie jest on nadludzkim wysiłkiem, ale drogą do osiągnięcia lepszego życia i perspektywy na przyszłość. Ta idea jest w Chinach głęboko zakotwiczona w kulturze i pamięci chińskiej (przypomnę, że od czasów Dynastii Sui, od 1400 lat). Mimo tego, iż od roku szkolnego 1998/99, po wprowadzeniu reformy dotyczącej jakości w edukacji w Chinach, rząd postanowił, że: (a) szkoły średnie będą wybierane poprzez rejonizację, a nie wyniki egzaminów, (b) zwiększy się liczba godzin wolnych od nauki, (c) ze szkół znikną rankingi oraz zajęcia pozalekcyjne, to Chińczycy nie potrafili zrezygnować z systemu egzaminacyjnego. W efekcie powstało potężne zaplecze edukacji pozaszkolnej (korepetycji, z j. angielskiego tzw. shadow education) organizowanej przez szkoły średnie dla przyszłych kandydatów (Zhang, 2014). W 2015 roku rząd chiński zabronił prawnie udzielania korepetycji nauczycielom ze szkół, do których uczęszczali ich uczniowie. Z potrzeby rynku powstały specjalne kursy przygotowawcze, organizowane przez topowe szkoły średnie lub pod ich patronatem, ale poza terenami szkoły. W tego rodzaju placówkach przygotowawczych organizowano także szereg olimpiad naukowych, na podstawie których laureaci otrzymywali symboliczne, złote legitymacje uczniowskie (rodzaj biletu wstępu) i stawali się uczniami najlepszych szkół. W związku z rejonizacją szkolną domy w okolicy najlepszych szkół średnich osiągają zawrotne ceny na rynku nieruchomości. Rodziny $\mathrm{z}$ dziećmi w wieku szkolnym potrafią zrezygnować $\mathrm{z}$ mieszkania $\mathrm{w}$ apartamentach o powierzchni $120 \mathrm{~m}^{2}$ na rzecz mieszkań $50 \mathrm{~m}^{2}$, jeżeli te znajdują się w pożądanej dzielnicy z najlepszą szkołą. Przeprowadzka najczęściej następuje w momencie, kiedy dzieci wkraczają w wiek rozpoczęcia edukacji podstawowej. Powszechne jest także grupowe kupowanie takich nieruchomości i meldowanie kilku rodzin na jednym adresie. Wskazane praktyki stanowią dowód zaangażowania Chińczyków w zapewnienie swoim dzieciom opty- 
malnej edukacji, zwiększanie ich szans edukacyjnych, i wynikają z głęboko zakorzenionych kulturowych przekonań, iż edukacja jest wartością najwyższą. Są także dowodem silnego urynkowienia tejże sfery życia.

Kolejnego przykładu dostarczają badania longtidualne nad kulturą edukacji przedszkolnej w trzech kulturach: Chinach, Japonii i USA autorstwa Josepha Tobina, Yeh Hsueha, Mayumi Karasawy (2011). Badania dotyczyły wpływów zmian globalnych na przeobrażenia w polityce edukacyjnej, podstawie programowej i kształceniu nauczycieli w latach 80. i później w 2009 roku w wymienionych krajach. W przypadku Chin okazało się, że kiedy w 1980 roku badacze odwiedzali placówki edukacyjne, zwrócili uwagę na nauczycieli, którzy kierowali wszystkimi aktywnościami dzieci, z potrzebami fizjologicznymi włącznie. Poznali ścisłe programy edukacyjne dla dzieci, uczniów śpiewających pieśni patriotyczne i wykonujących poranne ćwiczenia, według zaplanowanej rutyny i obowiązującej ideologii. Odnotowano silne kolektywistyczne praktyki, w porównaniu z indywidualistyczną kulturą Zachodu. $\mathrm{Na}$ rewizycie, po 20 latach, tylko poranna tradycja zbiorowych tańców i gimnastyki - guangbo ticao (w dosłownym tłumaczeniu: gimnastyka do muzyki z głośników) pozostała niezmieniona i do dziś jest praktykowana w chińskich przedszkolach i szkołach podstawowych. Tradycja guangbo ticao to synchroniczne ćwiczenia grupy osób, dziś raczej całe tańce w rytm muzyki chińskiej. Dawne metody „nauczyciela w centrum” i „bezwzględnego posłuszeństwa" zostały zmienione na metody pedagogiczne, z uwzględnieniem dziecka w centrum, na wzór zachodni, jednak... z zachowaniem chińskiego kontekstu. Zmieniono nazwę na określenie lekcji (ke), na aktywności dzienne (huodong), najmłodszych nie nazywa się uczniami (xuesheng), a po prostu dziećmi (er'tong). Mogłoby się wydawać, że w nowym przedszkolu chińskim, zorientowanym na ucznia, tradycja zbiorowej gimnastyki, wymagającej porządku, podporządkowania się zbiorowości oraz synchronizacji ciała i umysłu nie przetrwa próby czasu, jednakże guangbo ticao trwa i jest kultywowane. Hybryda chińskiej edukacji przedszkolnej stanowi przykład połączenia nowoczesności z tradycją, gdzie oba wpływy są równie widoczne. Chang Liu i Joseph Tobin (2016) w 2014 roku podjęli się próby przeanalizowania tradycji gungbo ticao w przedszkolach chińskich. Wyniki badań jasno przedstawiają, że tradycja guangbo ticao jest stałym elementem edukacji przedszkolnej w całych Chinach, na wsiach, w miastach, na prowincjach, co w przypadku zróżnicowanej mozaiki etnicznej Chin nie jest oczywiste. Fakt, że guangbo ticao jest praktykowany tak szeroko i konsekwentnie. jest w dużej mierze zasługą chińskich nauczycieli, którzy stale wprowadzają i wytrwale ćwiczą kolejne tra- 
dycyjne utwory chińskie. To z kolei sugeruje, że wspomniana praktyka służy ważnym celom i czerpie z wiedzy kulturowej, wartości i przekonań. Styl nauki zbiorowej gimnastyki w etapach i z ogromnym zaangażowaniem nauczyciela nawiązuje do tradycyjnej pedagogiki chińskiej: pomimo różnic każdy może się uczyć; nauczyciel musi opanować to, czego będzie uczył; uczeń tylko przez wysiłek może osiągnąć sukces. Inne badania autorstwa Jinling Tao i Jianjun Yin (2017) na temat kultywowania tradycji i kultury chińskiej w przedszkolach pokazały, że młodzi nauczyciele od 20. do 30. roku życia otwarcie przyznali, że nie posiadają wiedzy na temat tradycji chińskich i nie używają żadnych elementów kultury w edukacji dzieci, poza tradycją guangbo ticao. Połowa wszystkich osób badanych (wiek od 20. do 43. r.ż.) informowała, że w ich nauczaniu pojawiają się elementy kultury folkowej, przypowieści, pieśni czy zwyczaje powitania. We wspomnianych badaniach (Tao i Yin, 2017), w rekomendacjach, autorzy przestrzegają przed globalnymi trendami i wskazują na potrzebę zrewidowania chińskiej podstawy programowej dla przedszkoli, a szczególnie dokumentu dodatkowego, w którym znajdują się rekomendacje co do nauczania tradycji, kultury i wartości chińskich, pt. Complete Excellent Chinese Traditional Culture Guidance in 2014. Wskazują także na potrzebę włączenia środowiska lokalnego i zmianę w kształceniu nauczycieli.

Ostatni przykład nawiązuje do podporządkowania się uczniów woli nauczyciela i rodziców. W etyce konfucjańskiej podporządkowanie się jest elementem kodeksu postępowania. Uczniowie w Chinach, szczególnie w szkole średniej, w swojej biografii edukacyjnej podejmują się wykonywania zadań, które nie wynikają z ich woli i motywacji, ale chęci zwiększenia swoich szans edukacyjnych i podyktowane są posłuszeństwem wobec losu, który organizują im nauczyciele i rodzice. Dla przykładu, w Chinach powszechne jest praktykowanie dodatkowych zajęć lekcyjnych, po szkole i w weekendy. Uczniowie na zajęcia zapisywani są przez rodziców, którzy wraz z nauczycielami wybierają odpowiednie placówki. Wszystko dzieje się poza wolą ucznia, od którego oczekuje się uczestnictwa i zaangażowania. W przeprowadzonych przeze mnie badaniach nad społecznością studentów edukacji II roku Beijing Normal Uniwersity w Pekinie, które dotyczyły doświadczeń edukacyjnych studentów od czasu szkoły podstawowej do czasów obecnych, respondenci ${ }^{3}$ deklarowali, że zarówno oni, jak i wszyscy ich koledzy i koleżanki uczestniczyli w dodatkowych formach kształcenia poza szkołą średnią, które nie wynikały z ich zainteresowań. Takie zajęcia zajmowały czas do późnych

3 Grupą badaną były osoby pochodzące i wychowane w Pekinie. 
godzin nocnych, także w weekendy. Według opinii respondentów podejmowany wysiłek był uzasadniony przede wszystkim osiągnięciem lepszych rezultatów na egzaminie końcowym gaokao, ale także „oddaniem synowskim” i potrzebą podporządkowania się woli rodziców. Wszyscy jednakowo deklarowali, że był to czas pełen wyrzeczeń, inicjowany przez rodziców, ale nie interpretowali go w poczuciu krzywdy, lecz nadając mu sens i znaczenie. W wypowiedziach niektórzy respondenci podkreślali, że tę część ich biografii edukacyjnej podziela większość znanych im młodych Chińczyków. Zaznaczali, że bardzo często w możliwość pobierania nauki (już na studiach) zaangażowana (finansowo i emocjonalnie) jest cała rodzina, zarówno bliższa, jak i dalsza (np. wuj ze strony matki). Student ponosi fizyczne (np. zmęczenie, obniżenie odporności organizmu), psychiczne (obniżenie nastroju, epizody załamania nerwowego) i społeczne (brak przyjaciół, kontaktów koleżeńskich) koszty obciążenia hierarchicznością i wymaganiami, jednak godzi się na to i akceptuje ten fakt. Nie może zawieść najbliższych, ponieważ jeśli poniesie porażkę, to cała rodzina straci „twarz” w oczach społeczności lokalnej. W głosach respondentów wyraźnie słyszalne było pogodzenie się z obowiązującymi normami i kulturą.

\section{Zakończenie}

W powyższym artykule zaprezentowano chińskie podejście do zmian globalizacyjnych w obszarze edukacji. We wspomnianych procesach globalizacyjnych charakterystyczne są napięcia pomiędzy kulturową homogenizacją a kulturową heterogenizacją. Przykłady z Chin pokazały, że globalne trendy edukacyjne zostały przefiltrowane przez chiński kontekst. Chiny posiadaja silne uwarunkowania kulturowe i polityczne, dlatego w przypadku Państwa Środka dominacja globalnej kultury nad kulturą lokalną jest mało prawdopodobna. Roland Robertson (2012) na opisanie tego zjawiska wprowadził termin glokalizacji, który wyjaśnia paradoks relacji pomiędzy homogenicznością a heterogenicznością kulturową. George Ritzer (2003) z kolei wyjaśnia, że glokalizacja to nic innego jak interpretacja globalnego i lokalnego, co w rezultacie daje różne kombinacje w odmiennych częściach świata. Okazuje się, że w takim rozumieniu globalne i lokalne nie wykluczają się, ale tworzą swojego rodzaju hybrydę. Joseph Tobin i Chang Liu (2018) nazywają to zjawisko kontektstualizacją, a w języku chińskim zjawisko to ma swoją nazwę ben-tu-hua, gdzie dominuje pogląd mówiący, że zachodnie praktyki edukacyjne nie powinny być traktowane jako wzorcowe. W Chinach dokonuje 
się dostosowania ich do wymogów lokalnych. Jak wynika z przedstawionych w artykule przykładów, Chiny bardzo mocno zakorzenione są w koncepcji kontekstulizacji. Charakteryzuje je lokalne podejście do edukacji - łączenie zachodnich pomysłów z chińską tradycją.

\section{Bibliografia}

Bruner, J.S. 2006. Kultura edukacji. Kraków: Universitas.

Choy, G. 2017. Chinese Culture in Early Educational Environments. In: Rao, N., Sun. J. and Zhou, J. eds. Early Childhood education in Chinese societies. Hong Kong: Springer, pp. 31-52.

Cohen, Y. 1971. The shaping of man's mind: adaptations to imperatives of culture. In: Wax, M., Diamond, S. and Gearing, F. eds. Anthropological perspectives on education. New York: Basic Books, pp. 19-50.

Curriculum Development Council, 2017. Kindergarten Education. Curriculum Guide, https://www.edb.gov.hk/attachment/en/curriculum-development/major-level-of-edu/preprimary/KGECG-En-Draft-2017.pdf (6.05.2020).

Gromkowska-Melosik, A. 2018. Testy edukacyjne Studium dynamiki selekcji i socjalizacji. Poznań: UAM.

Gu, M. 2014. Cultural Foundations of Chinese Education. Boston: BriLL.

Hofstede, G., Hofstede, G.J. i Minkow, M. 2011. Kultury i organizacje. Warszawa: PWE.

Kessing, R.M. 1980. Cultural Anthropology. New York: Rinehart and Winston.

Kluckhohn, F. 1961. Dominant and variant value orientations. In: Kluckhohn, F.F. and Strodtbeck, F.L. eds. Variations in value orientations Westporst: Row, Peterson and Company, pp. 1-48.

Liu, Ch. and Tobin, J. 2018. Group Exercise in Chinese Preschools in an Era of Child-Centered Pedagogy. Comparative Education Review. 1 (62), pp. 5-30.

Mańkowska, A. 2017. Językowa rzeczywistość edukacyjna w wielokulturowych Chinach. Jedność czy różnorodność? Pedagogika Szkoty Wyższej. 2 (22), ss.121-132.

Manzon, M. 2018. Origins and traditions in comparative education: challenging some assumptions. Comparative Education. 1 (54), pp. 1-9.

Mead, M. 1943. Our Educational Emphases in Primitive Perspective. American Journal of Sociology. 6 (48), pp. 633-639. 
Redcliffe-Maud, J. 1973. Master Sadler after 50 years. University College Record. 6 (3), pp. 250-253.

Ritzer, G. 2003. Rethinking Globalization: Glocalization/Grobalization and Something/Nothing. Sociological Theory. 3 (21), pp. 193-209.

Ritzer, G. 2009. Makdonaldyzacja społeczeństwa. Warszawa: Muza.

Robertson, R. 1992. Globalization: Social Theory and Global Culture. London: Sage.

Robertson, R. 2012. Globalisation or glocalisation? The Journal of International Communication. 2 (18), pp. 191-208.

Sztompka, P. 2002. Socjologia. Analiza społeczeństwa. Kraków: Oficyna Wydawnicza „Impuls”.

Tao, J. and Yin, J. 2017. A Study on Chinese Traditional Culture Education in China's Kindergartens. International Journal of Humanities Social Sciences and Education. 3 (4), pp. 59-66.

Tobin, J., Hsueh, J. and Karasava, M. 2011. Preschool in Three Cultures Revisited: China, Japan and the United States. Chicago: University of Chicago Press.

Yang, W. and Li, H. 2019. Early Childhood Curriculum in Chinese Societies. Hong Kong: Routledge.

Zhang, W. 2014. The demand for shadow education in China: mainstream teachers and power relations. Asia Pacific Journal of Education. 4 (34), pp. 436-454.

\section{Globally or locally? Cultural determinants of education in China}

Abstract: The purpose of this article is to present the cultural determinants of education in China in the age of globalization. The article answers the question whether in times of global change and the free flow of culture and educational solutions, education in China remains faithful to local tradition and values. The subject of the study is the educational system and cultural and social reality in the era of change. The article uses the existing studies and research of Chinese and foreign authors. The scientific method at this article is analyze of secondary sources. Analyses have shown that despite rapid global changes, Chinese education in its methods and teaching methods remains faithful to the ideals and assumptions of Chinese identity, and does it through the process of contextualization.

Keywords: comparative education, China, education in China, globalization 